\title{
Pseudophaco-anaphylactic endophthalmitis?*
}

\author{
J. Reimer Wolter \\ The Departments of Ophthalmology and Pathology of the University of Michigan Hospitals, Ann Arbor, Michigan 48109, USA
}

\begin{abstract}
The pathology of subacute granulomatous endophthalmitis centered on a posterior chamber lens implant placed at extracapsular cataract surgery in the eye of a 72 year-old diabetic with cystoid macular edema following intracapsular extraction and an anterior chamber implant in the other eye is described in detail 3 months after surgery. The features of the severe granulomatous inflammation do not fit the usual pattern of sympathetic or phacoanaphylactic uveitis. The possibility of a specific hypersensitivity to the substance of the implant is considered.
\end{abstract}

Zusammenfassung. Die Pathologie von subakuter Endophthalmitis in einem Fall von einem Hinterkammerlinsenimplant nach extrakapsulaerer Kataraktexctraktion im Auge einer 72jährigen Diabetikerin mit zystoidem Makulaödem nach intrakapsulärer Kataraktoperation und Vorderkammerlinsenimplant im anderen Auge wird drei Monate postoperativ in allen Einzelheiten beschrieben. Das Bild einer schweren granulomatösen Entzündung paßt nicht zu den Diagnosen von symphatischer oder phakoanaphylaktischer Uveitis. Die Möglichkeit einer spezifischen Hypersensitivität gegen die Substanz des Implants wird in Betracht gezogen.

Everytime an eye surgeon places an intraocular lens implant, he opens a Pandora's box of complex and potentially dangerous ocular reactions. The marvelous mechanisms for defense and adjustment of the inner eye usually keep these reactions under control and prevent serious functional defects. However, histopathologic study of clinically successful cases shows that chronic inflammation persists in all eyes with implants. Histological evaluation usually places the intraocular inflammation seen in association with lens implants by its classification in a border zone somewhere between foreign body reaction and chronic granulomatous inflammation [1-9]. The nature of the uveal infiltration in these eyes usually is of a non-granulomatous type. However, large giant cells are common on the surface of lens implants. These frequently contain pigment granules in their protoplasm and do not always resemble simple

* Supported by the Research To Prevent Blindness, Inc., New York

Offprint requests to: J. Reimer Wolter, MD foreign body giant cells. Some of these cells look like Touton giant cells and have a central accumulation of nuclei. The giant cells are usually associated with epitheliod cells, macrophages in different stages of activity, and other types of mononuclear cells. Polymorphnuclear inflammatory cells (PMN's) are not a common component of reactive cellular membranes on the surface of lens implants.

To present a case of subacute granulomatous endophthalmitis with Langhans giant cells and PMN's centered on a posterior chamber lens implant placed after extracapsular cataract extraction is the purpose of the present paper.

\section{Case report}

This 72 year-old white female patient with a twelve-year history of Insulin-dependent diabetes mellitus had an intracapsular cataract extraction with an anterior chamber lens implant in her left eye done by a North Carolina ophthalmologist in September 1981. The patient is said to have done well with this, until she developed cystoid macular

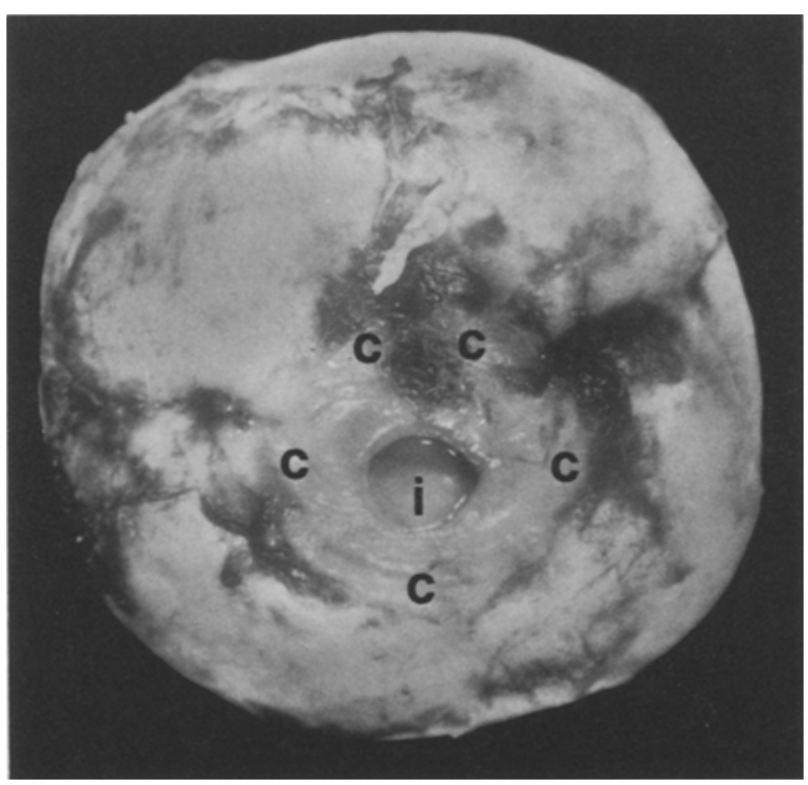

Fig. 1. Frontal view of the eyeball with the surface of the lens implant $(i)$ visible in the depth of the central corneal perforation. The outer limits of the cornea are indicated by five $c$ 's. - Gross photograph $\times 4$ 


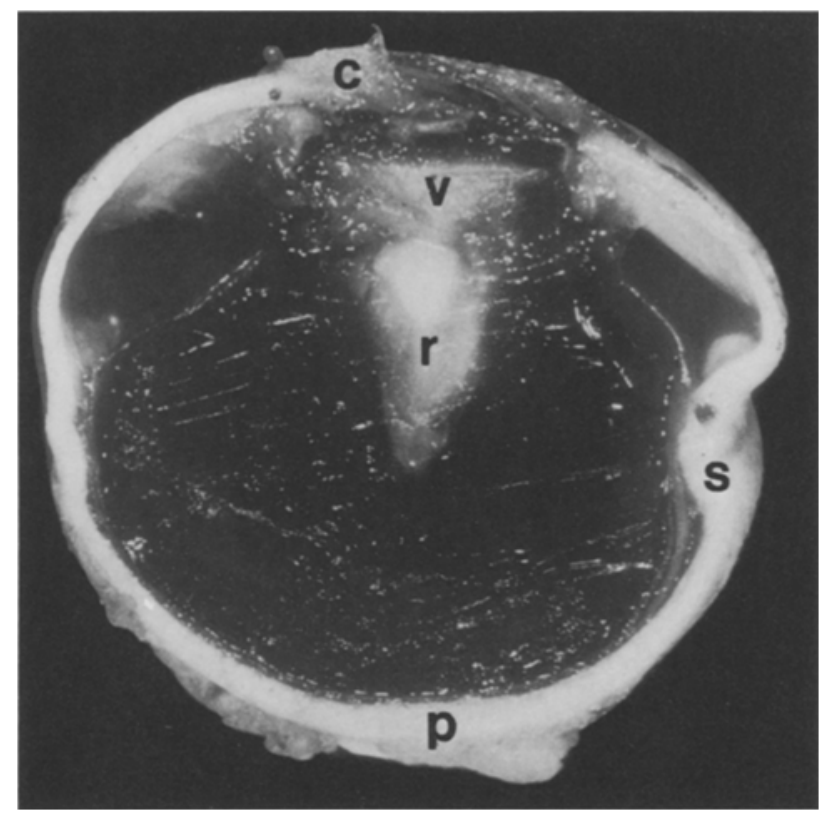

Fig. 2. The globe opened in a horizontal plane with the defective cornea $(c)$, the shrunken vitreous $(v)$ and retina $(r)$, the folded sclera $(s)$, and the dark retroretinal exudate. The chorod is not thickened and the optic nerve is contained in the posterior sclera (p). - Gross photograph $\times 3,6$ edema in the left eye causing decrease of central vision to around $20 / 100$ in January 1882 . Next, an extracapsular cataract extraction with a posterior chamber lens implant was done in the right eye in September 1982 by the same eye surgeon. On the third postoperative day a ring abscess of the cornea associated with a hypopyon developed in this right eye and a proteus endophthalmitis was diagnosed. Vigorous antibiotic treatment and a vitrectomy were done, but the patient soon lost all vision in the right eye. A central corneal ulcer was recognized at that time and was called a neurotrophic ulcer by the surgeon. The patient changed physicians and went to see Harry Bash, M.D. of Findlay, Ohio. Dr. Bash found in the right eye a corneal perforation with central exposure of the lens implant, blindness, early phthisis, and severe irritation. He enucleated the eye on 12.14.82 and immediately fixed it in Formalin.

The eye measured $19 \times 22 \times 23 \mathrm{~mm}$. The central cornea was missing and the optic portion of a plastic implant was exposed (Fig. 1). When the eye was opened in the horizontal plane, the lens implant was found firmly attached to the borders of the remaining cornea and its peripheral and posterior aspects were firmy encorporated in scar tissue. This scar tissue filled the region of the anterior chamber and it was continuous with a scar that replaced the totally collopsed and organized vitreous (Fig. 2). The retina was part of this organized scar. The retroretinal space contained exudate of dark-brown color. The choroid was in place

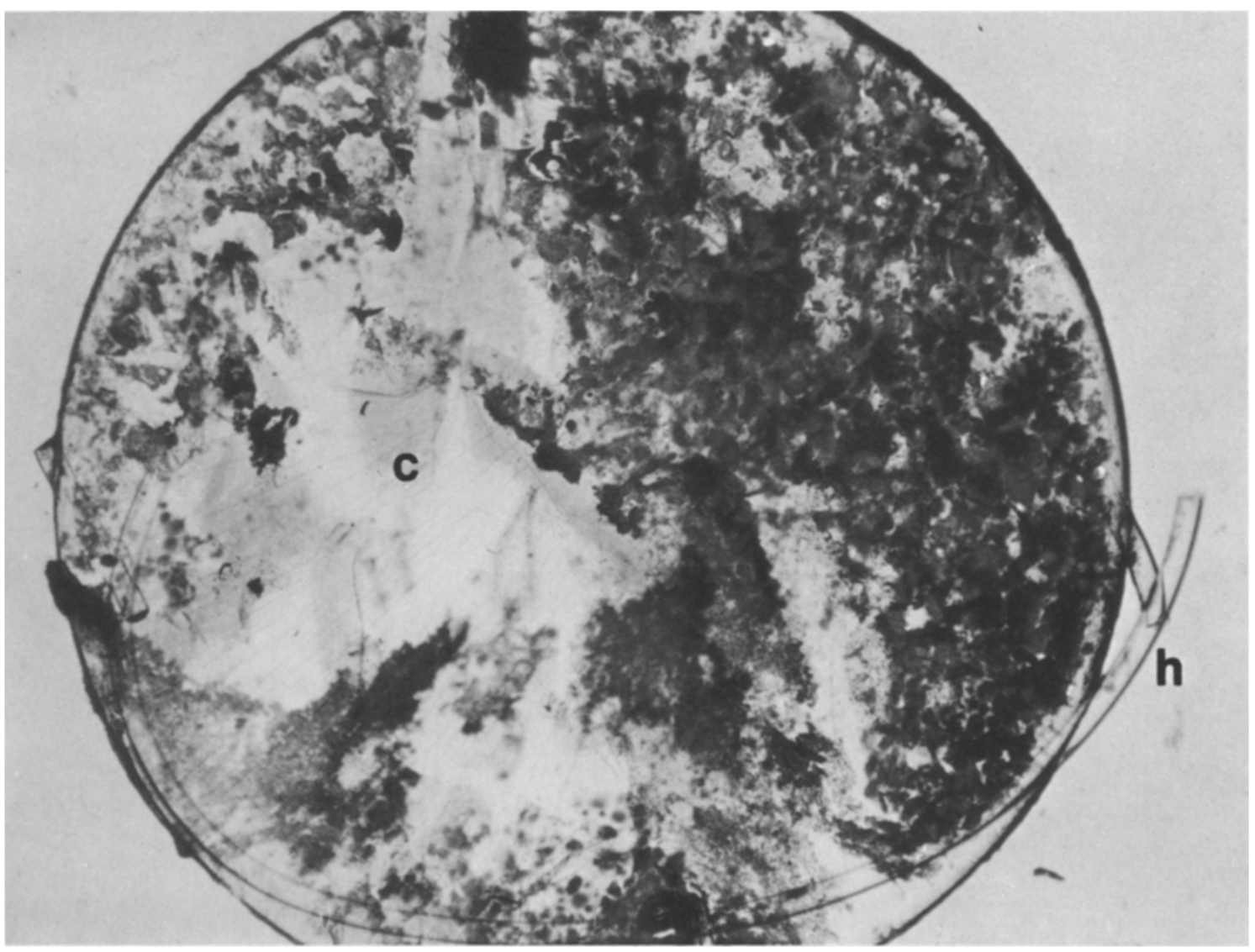

Fig. 3. The lens implant with its broken haptics $(h)$. A continuous capsule $(c)$ containing a monolayer of large cells covers all of the implant. - Implant cytology technique, $\mathrm{H}$ and $\mathrm{E}$ stain, photomicrograph $\times 25$ 


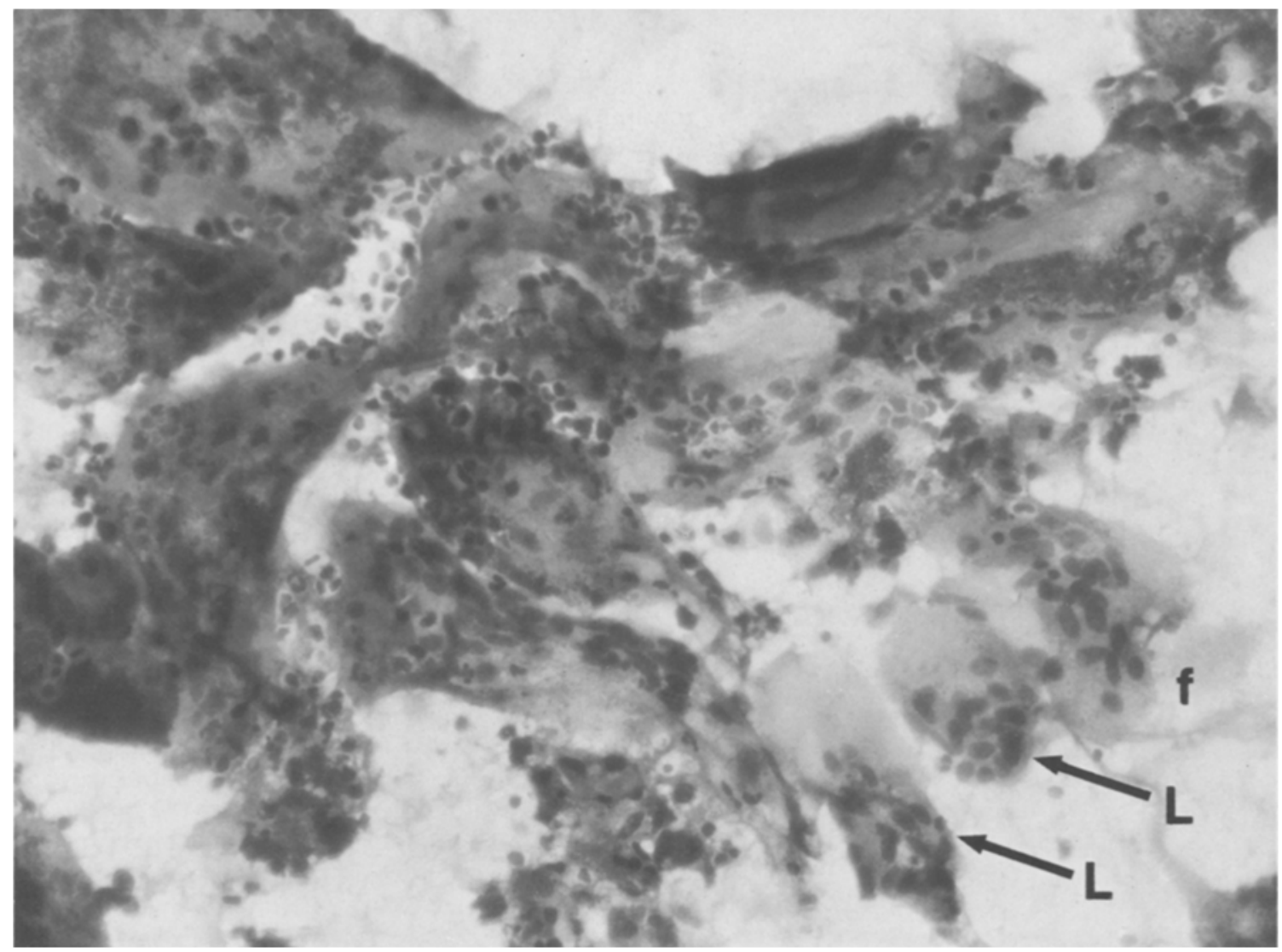

Fig. 4. High power of densely arranged foreign body giant cells $(f)$ on the surface of the present implant. Two marginal cells show movement of nuclei to the protoplasmic border in the process of developing into Langhans cells $(L)$. - Implant cytology technique, $\mathrm{H}$ and $\mathrm{E}$ strain, photomicrograph $\times 225$

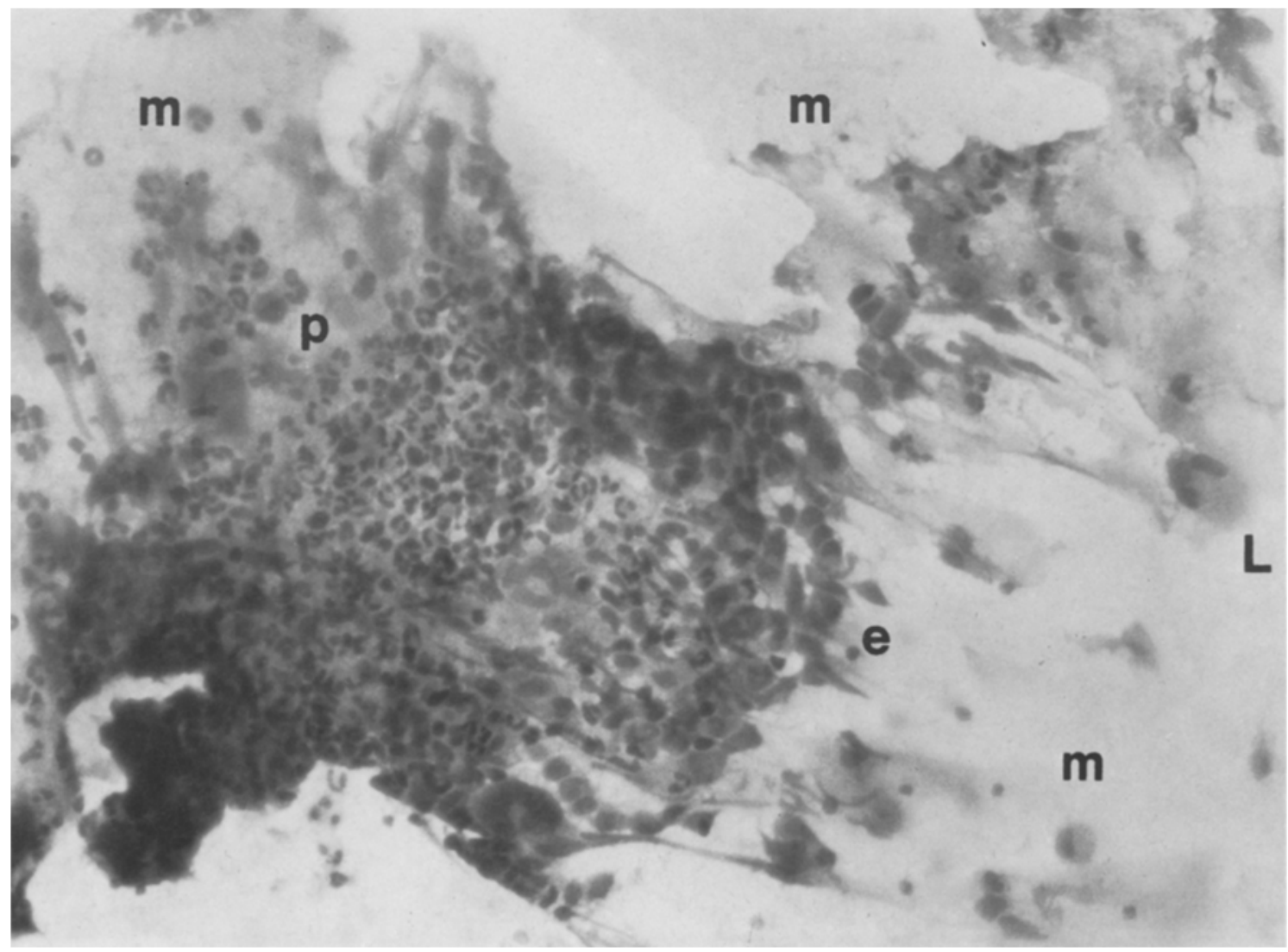

Fig. 5. Surface of the lens implant with an accumulation of densely arranged PMN's $(p)$ surrounded by a margin of epithelioid cells $(e)$. One small Langhans cell $(L)$ is seen on the right. The capsular membrane $(m)$ on the plastic surface of the implant varies in its thickness and eosinophilic stain. - Implant cytology technique, $\mathrm{H}$ and $\mathrm{E}$ stain, photomicrograph $\times 225$ 


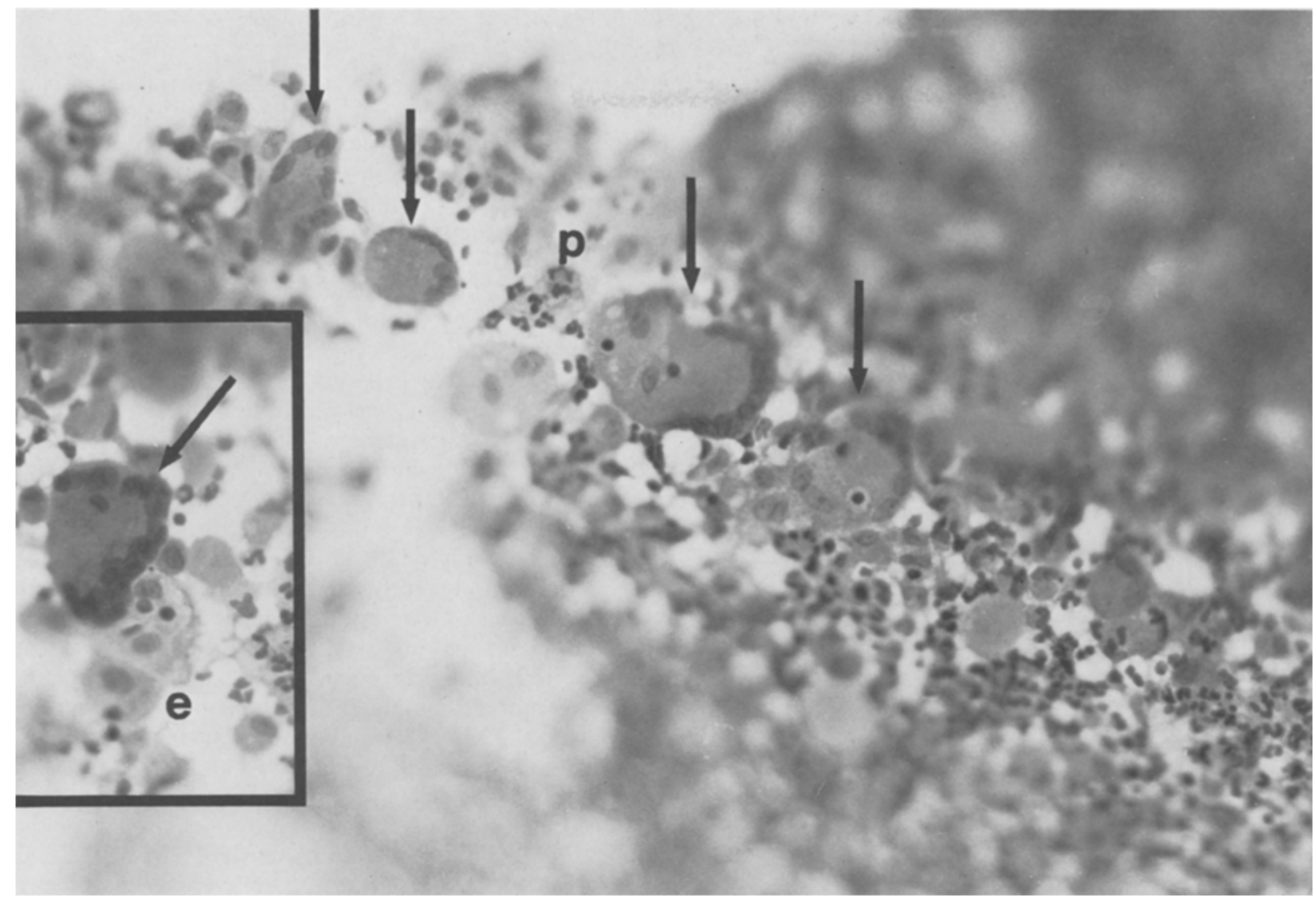

Fig. 6. Langhans giant cells (arrows) as part of the monolayer of cells on the implant. The cells in the inset needed different focusing. PMN's $(p)$ and eosinophilic epithelioid cells $(e)$ are seen around the Langhans cells. - Implant cytology technique, H and E stain, photomicrograph $\times 225$

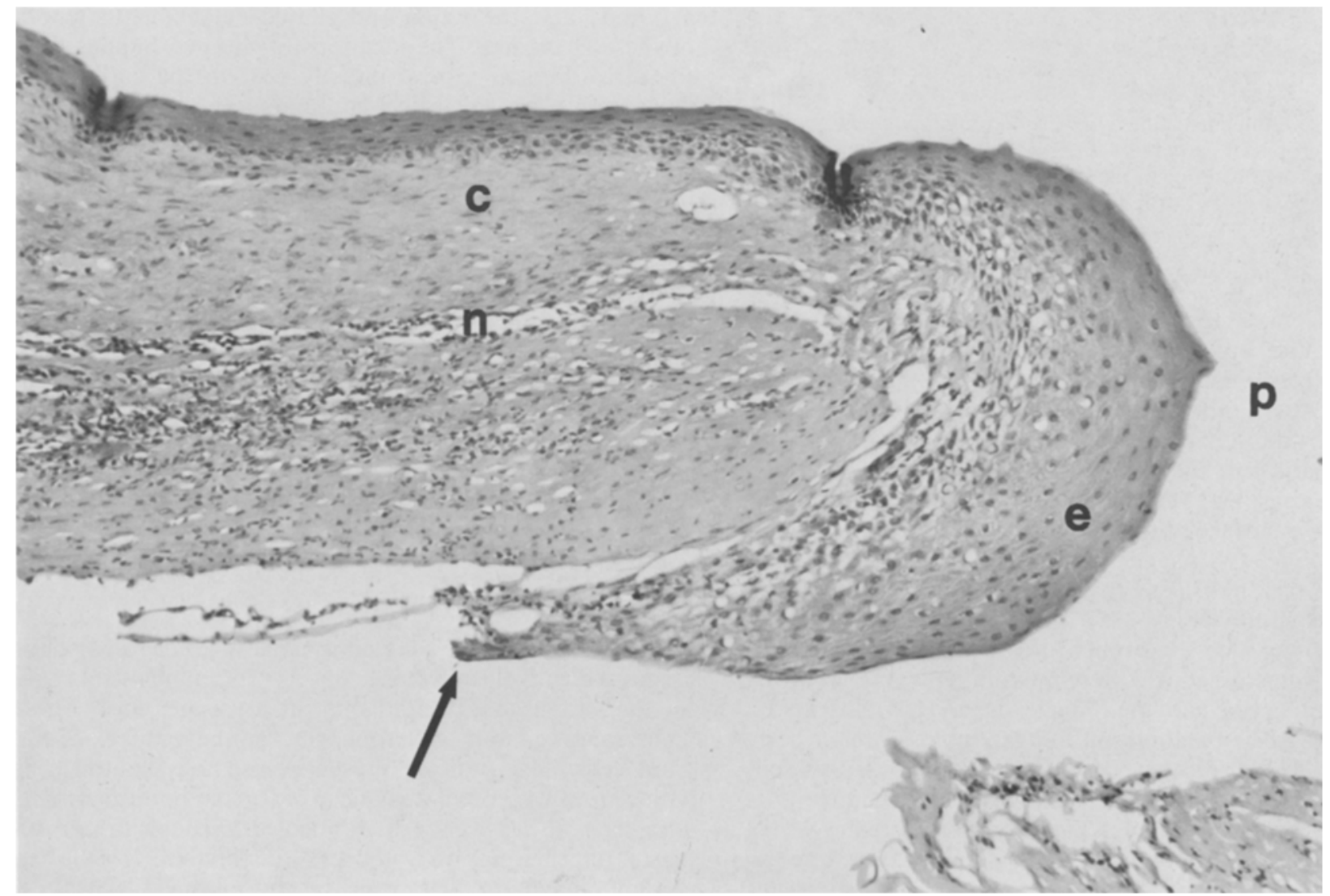

Fig. 7. Border on one side of the corneal ulcer with perforation $(p)$, corneal stroma $(c)$ with neovascularization $(n)$, and early epithelial downgrowth (e) onto the posterior corneal surface (arrow). - Paraffin section, $\mathrm{H}$ and $\mathrm{E}$ stain, photomicrograph $\times 125$ 


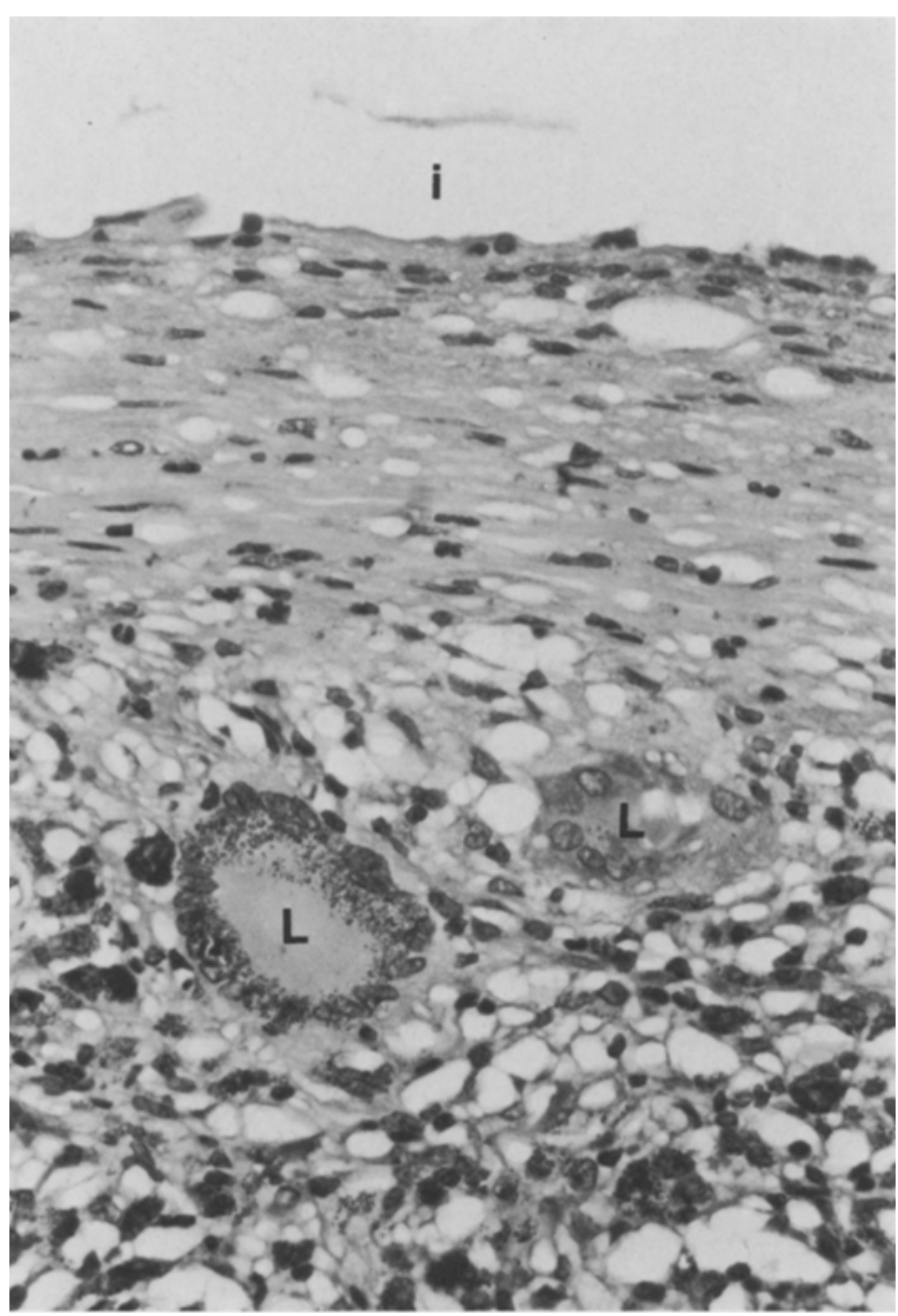

Fig. 8. Large Langhans giant cells $(L)$ containing pigment granules in their protoplasm as part of the granulomatous reaction in the leyer of scarring posterior to the implant. The space of the implant (i) is seen above. - Paraffin section, $\mathrm{H}$ and $\mathrm{E}$ stain, photomicrograph $\times 260$

and the sclera exhibited the folding that is typical for early phthisis. The optic portion of the implant was easily removed from the cornea and the surrounding scar tissue. However, the haptics were firmly embedded in the tough scar tissue and they broke in the removal process.

Application of the lens implant cytology technique [2] revealed a thick and very cellular reactive membrane covering all of the surface of the implant in a somewhat irregular manner (Fig. 3). This membrane was, in the first place, composed of a film-like capsule of irregular thickness and eosinophilic stain (Figs. 3-5). An irregular monolayer of celluar elements covered much of its surface. Large giant cells with numerous nuclei were predominant (Fig. 4). Most of the giant cells had their nuclei irregularly distributed all through their protoplasm and resembled foreign body giant cells. However, there also were giant cells with a centrally clear protoplasm and a row of nuclei occupying its peripheral protoplasm in a more or less well developed horseshoe- or ring-shape (Figs. 4-6). Zones of the monolayer contained sheets of polymorphnuclear leucocytes (Fig. 5), and epithelioid cells exhibiting the pattern of typical zonal granulomatous reaction were often seen next to these accumulations of PMN's (Fig. 5). In the areas with PMN's there also were very well developed giant cells of the Langhans type with typical ring- or horsehsoe-shaped arrangement of the nuclei in the periphery of their protoplasm (Fig. 6). Highly eosinphilic epithelioid cells of large size also were associated with the groups of the Langhans cells and the PMN's (Fig. 6). It is important to emphasize that all these cells were part of the monolayer and firmly adherent to the optic portion of the implant. It is also important to state that the surface of the eosinophilic capsule did not exhibit any cells in several areas and that the capsular part of the membrane was very thin in these parts without cells (Fig. 5). The remnants of the removed portions of the broken haptics did not show evidence of a reactive membrane when they were studied with the implant cytology technique (Fig. 3).

Histological study of the globe revealed absence of the central cornea with an early stage of epithelial downgrowth around the border of the perforated ulcer (Fig. 7). The corneal endothelium was gone and it was replaced by a scar membrane that had firmly surrounded the lens implant. This scar membrane contained additional giant cells, epithelioid cells, and PMN,s on and near its surface. The giant cells partly were typical Langhans cells and they contained pigment granules in their protoplasm (Fig. 8). Lens capsule and some cortical lens remants were found in back of the implant (Fig. 9). These lens remnants were part of the scar that surrounded the implant, but there were no giant cells, epithelioid cells, or PMN's seen on or next to these remnants of the original cataract. The scar membrane around the implant was continuous with additional scarring in the region of the organized vitreous. This had involved the ciliary body and the retina and caused detachment of both of these structures. The locations of the two haptics were found in the scar almost directly next to the cornea and these were surrounded by a continuous ring of granulomatous reaction with giant cells - at least as large as those seen on the optic part of the implant (Fig. 10). The retroretinal space was filled with a serous exudate containing blood. The choroid was of normal thickness and exhibited only slight mononuclear infiltration. The optic nerve showed atrophic changes and the thickened sclera was not involved by inflammation. The cytological and histological studies, thus, resulted in a diagnosis of: subacute granulomatous endophthalmitis centered on a lens implant in an eye also exhibiting corneal perforation, obliteration of the anterior chamber, evidence of extracapsular cataract surgery, organisation of the vitreous, detachment of ciliary body and retina, slight non-granulomatous choroiditis, and early phthisis.

\section{Discussion}

All eyes with implants have signs of a low-grade iridocyclitis associated with clear evidence of cell-containing membranes on the surface of the implants, in my experience. These membranes contain macrophages, epithelioid cells, and giant cells. The giant cells usually resemble Touton cells with centrally accumulated nuclei or foreign body giant cells with their nuclei evenly distributed all through the protoplasm, but their nature is not really understood. They often contain pigment in their extensive protoplasm [5]. The present trend in Ophthalmology in some parts of the world is to consider this low-grade reaction less of a nuisance 


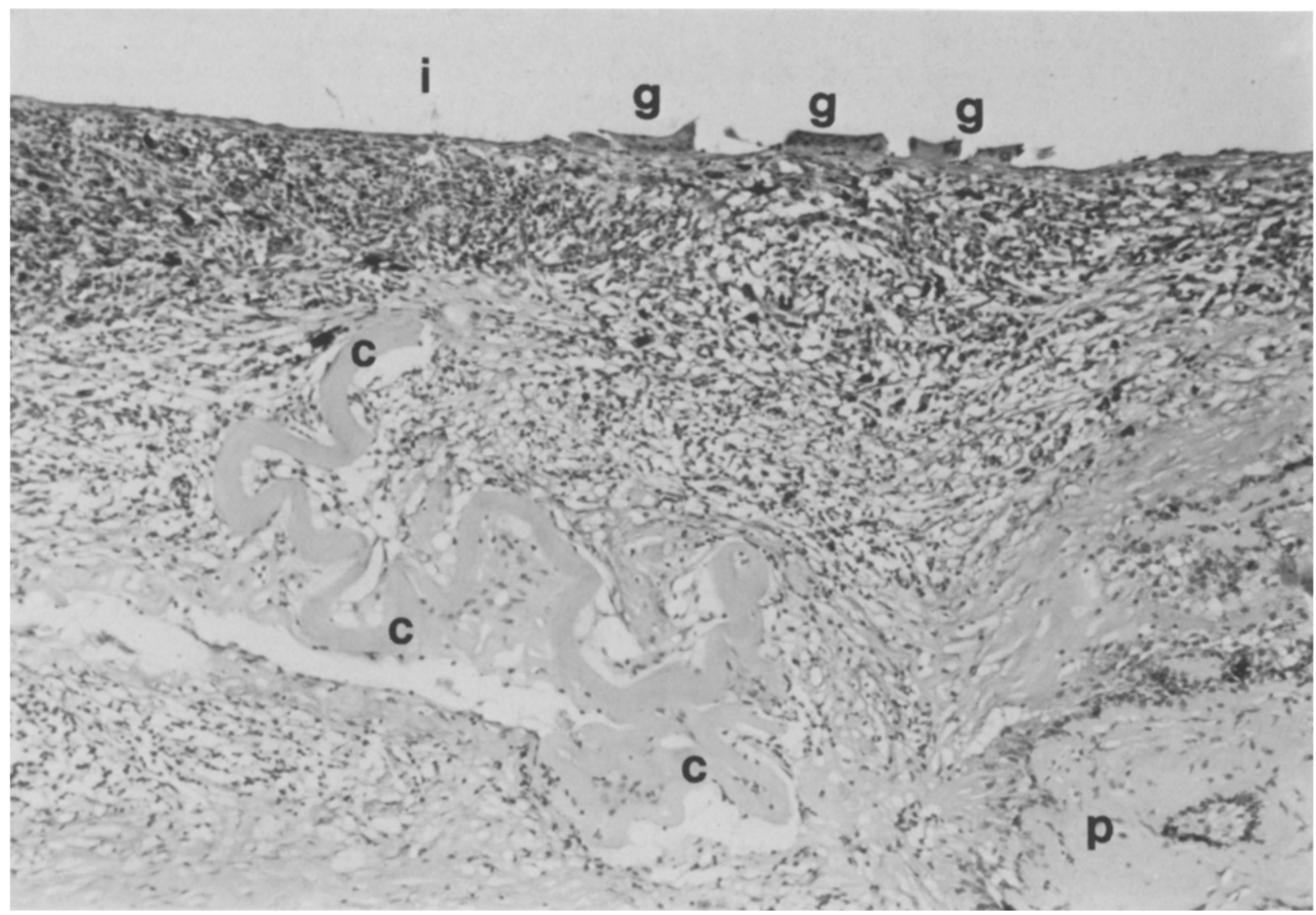

Fig. 9. Layer of scarring in back of the implant space ( $i)$ with several of the giant cells $(g)$ that have been lining the surface of the implant seen in cross section. The inflammatory reaction is granulomatous next to the implant. Remnants of the lens capsule (c) do not show adjacent granulomatous inflammation. A ciliary process is contained in the scar $(p)$. Paraffin section, H and $\mathrm{E}$ stain, photomicrograph $\times 100$

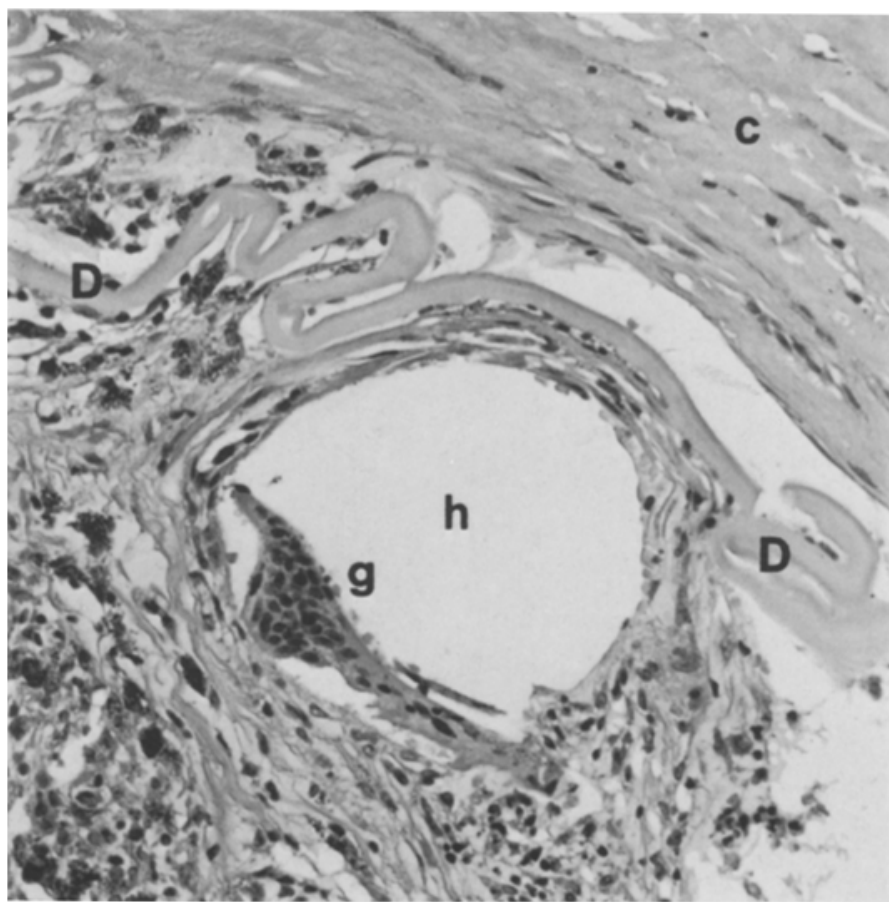

Fig. 10. Space of the loop-like haptic of implant (h) with large giant $(g)$ cell in its wall. This sits directly next to Descemets membrane $(D)$ of the cornea $(c)$. Paraffin section, $\mathrm{H}$ and $\mathrm{E}$ stain, photomicrograph $\times 225$ than the trouble of contact lens-wearing or the cosmetic handicap of thick glasses.

The disease processes in both eyes of the present patient certainly are more than a nuisance. Cystoid macular edema following intracapsular cataract extraction with an anterior chamber lens has caused loss of central vision in the right eye. Extracapsular cataract surgery with a posterior chamber implant done one year later in the left eye was complicated by an acute endophthalmitis that was diagnosed and treated as a bacterial infection and caused loss of the eye. Cytological and histological study of the right eye about three months after cataract surgery reveals facts that are of the greatest interest - independenat of the true nature of the acute postoperative reaction.

The present eye allows for the first detailed pathological study of a severe subacute granulomatous endophthalmitis that has its reaction centered on the implant - not on lens remnants and not on uveal pigment. Some of the giant cells found on and next to the implant in this eye are true Langhans giant cells - not foreign body giant cells and not multinuclear cells resembling Touton cells. These Langhans cells are directly associated with accumulations of PMN's. The fact that many of these Langhans cells contain pigment granules - just like those of sympathetic uveitis - adds to the confusion. An eye with an acute postoperative endophthalmitis is not in a typical situation for the development of sympathetic uveitis anyway - and the disease process in the present case also looks different than 
that of typical sympathetic disease due to hypersensitivity to uveal pigment and of phacoanaphylactic endophthalmitis due to hypersensitivity to degenerating lens substance. The difference mainly lies in the fact that the severe granulomatous reaction in the present case is partly acute, it is found directly on the surface of the plastic material of the implant, - and it decreases in severity, as one progresses in the surrounding scar tissues in a direction away from the implant. The relatively slight involvement of the choroid also does not fit the picture of sympathetic endophthalmitis.

It is interesting, for a moment, to consider the fact that the cornea turned necrotic in the region overlying the center of the implant in the present case. I have seen the same development in a few cases now. When an implant moves forward and attaches itself to the posterior corneal surface, it cuts off the nutritional supply to the corneal stroma. The central cornea turns necrotic and the implant appears somewhat like a keratoprothesis in the depth of the developing corneal ulcer. In this process the implant typically seals off the anterior ocular surface and temporarely prevents rupture and collapse of the globe. Chances are that the clinical observation of the "neurotrophic corneal ulcer" in this case coincided with the loss of anterior chamber and the attachment of the implant to the posterior corneal surface. With time, epithelial downgrowth found a way to extend into the eye around the borders of the corneal ulcer and caused these to look round and smooth. The capsular portion of the membrane on the implant is not very well developed in the present case. It is of irregular thickness and it is quite eosinophilic. Earlier studies have shown that a somewhat friable capsule of eosinophilic stain can be present after three month under usual postoperative conditions $[7,10]$. The fact that any kind of capsule could form within three month on the present implant under the rather turbulent conditions is remarkable.

The present case will cause us to study the question whether or not lens implants really always are immunologically inert. Or is it possible that patients can develop a specific hypersensititity to one of the plastic components?
Are the giant cells which are commonly found on lens implants in human eyes only signs of simple foreign body reaction; or do these unusual cells indicate a low grade hypersensitivity? In their surprizing multitude and complexity, the possible pathological reactions to intraocular lens implants certainly do resemble the contents of Pandora's box. However, it seems that just like in Pandora's box, there is hope at the bottom of the pile of possible complications, when everyone of these will be carefully studied and analyzed in its cause and nature and when ways will be found and rules will be followed to avoid them.

\section{References}

1. Kincaid MC, Green WR, Iliff WJ (1982) Granulomatous reaction to Choyce style intraocular lens. Ophthalmic Surg 13:292-299

2. Wolter JR (1982) Lens implant cytology. Ophthalmic Surg 13:939-942

3. Wolter, JR (1982) Cell life on the surface of lens implants. von Graefe's Arch Opth 218:244-249

4. Wolter JR (1982) Foreign body giant cells on intraocular lens implants. von Graefe's Arch Ophth 219:103-111

5. Wolter JR (1982) Pigment in cellular membranes on intraocular lens implants. Ophthalmic Surg 13:726-732

6. Wolter JR, Felt DP (1983) Proliferation of fibroblast-like cells on failing intraocular lenses. Ophthalmic Surg 14:57-64

7. Wolter JR (1983) Reactive membrane on a lens implant: three months after implantation. von Graefe's Arch Ophth (in print)

8. Wolter JR (1983) Foreign body giant cells selectively covering haptics of intraocular lens implants: indicators of poor toleration? Ophthalmic Surg (submitted)

9. Wolter JR (1983) Foreign body reaction to firm nuclear lens substance. Ophthalmic Surg 14:135-138

10. Wolter JR (1983) Morphology of the capsule-like portion of the reactive membranes on intraocular lens implants. von Graefe's Arch Ophth (submitted)

Received February 3, 1983 